Article

\title{
Design for Breathtaking Experiences: An Exploration of Design Strategies to Evoke Awe in Human-Product Interactions
}

\author{
Jialin Ke and JungKyoon Yoon * \\ Department of Design + Environmental Analysis, Cornell University, Ithaca, NY 14853, USA; jk2663@cornell.edu \\ * Correspondence: jy846@cornell.edu
}

Received: 11 October 2020; Accepted: 19 November 2020; Published: 24 November 2020

check for updates

\begin{abstract}
From looking up at a skyscraper to the Grand Canyon's vastness, you may have experienced awe in one way or another. Awe is experienced when one encounters something greater or more powerful than themselves and is associated with prosocial behavior through a diminishment of self-importance. In design research, most studies on awe have been conducted in lab conditions by using technologies such as virtual reality because of its efficiency to simulate typical awe-stimulating conditions (e.g., nature scenes). While useful in inducing awe and assessing its effects on users, they give little guidance about how design can deliberately evoke awe. Most attempts focus on the response of awe instead of its eliciting conditions. With an aim to support designers to facilitate awe, this paper explores design strategies to evoke awe. Based on appraisal theory, the cause of awe was formulated, and its relevance to designing for awe was investigated. The conditions that underlie awe in design were explored through a survey in which participants reported 150 awe experiences, resulting in six design strategies. The paper describes these strategies and discusses how they can be used in a design process, giving attention to addressing the experiential value of awe.
\end{abstract}

Keywords: design for emotion; positive emotion; awe; appraisal theory; design strategy; subjective experience; experience design

\section{Introduction}

Positive emotions improve our health and well-being through broadening our mindsets, promoting creativity and bonding, allowing us to build our long-term intellectual, social, and psychological resources [1]. These beneficial effects have increased interest in designing for positive emotions [2]. More recently, designers are investigating how to elicit discrete and distinct positive emotions, such as pride [3], fascination [4], and surprise [5], because of their unique beneficial functions. Specifically, the emotion of awe is being increasingly explored for its transformative potential and is considered highly relevant to design regarding its effect on users' behaviors [6]. Awe is considered transformative because it can reshape an individual's worldviews, and change one's perspective and identity [7]. Awe's transformative power lies in its ability to take our breath away and make us feel mind-blown as we try to accommodate these new stimuli into our schema, a mental structure that helps us understand the world. Awe is an emotion that can be characterized by feelings of wonder and surprise, and is often felt in experiences involving nature, religion, spirituality, art, music, and architecture [8]. Awe has unique beneficial functions such as making people more prosocial, diminishing their sense of self, which results in certain behavior tendencies such as inclinations to share, collaborate, and engage in collective action [9]. Another beneficial function is that people feel more connected to others and view themselves as part of a larger entity such as "member of the universe" or "inhabitant of the earth" [10]. Awe even reduces aggressive behaviors [11] and promotes green consumption [12]. More importantly, 
evoking awe has the potential to contribute to the well-being of oneself as well as to a collective [8]. Awe has shown to increase experiential creation, making people open to learning; and increasing their tendency to favor experiential products over premade ones [13].

To date, in design research, most studies on awe have been conducted in lab conditions, by using technologies such as Virtual Reality (VR) e.g., [14,15]. Virtual environments are believed to have a high potential to evoke awe and is a commonly chosen tool because of its efficiency to generate presence, immersion, and create an "other-than-self" experience for epistemic expansion [6]. However, this conventional approach would give little guidance for designers who want to create things that facilitate the experience of awe in the real world beyond highly controlled lab conditions. While VR can serve as an effective medium through which an awe experience can manifest, simulating suggestive awe-eliciting conditions would not inform how awe can be deliberately designed for. In addition, most attempts to elicit awe use nature imagery, whether its $2 \mathrm{D}$ images or videos, or 3D in a VR environment e.g., $[9,14]$. By only using nature imagery, the awe elicitation method focuses on only one aspect of the definition of "vastness," the literal size and physicality, even though vastness can be anything that is "much larger than self, or the self's ordinary level of experience" [8]. There is a wide range of awe elicitors beyond nature, including interpersonal elicitors, collective activities such as rallies and sports games, spiritual experiences, and cultural artifacts [16], but they have been largely unexplored in design. Although some awe-evoking art objects that go beyond nature imagery exist (for an overview of such examples, see [17]), they rarely explicate how they were created and provide few references to the underlying decisions in the process. Thus, while they offer designers inspiration to design for awe, they do not offer an explicit approach to achieve the intended emotional impact (i.e., elicitation of awe). This implies creating an awe experience in human-product interactions can still be challenging for those who want to evoke awe and utilize its experiential effects through their designs.

This paper aims to explore design strategies to design for awe, so that it can serve as a reference for designers to develop an understanding of the experience of awe in human-product interactions and how awe can be purposefully evoked through design. Here, we define design strategies as pathways that designers can take to reach a design goal (both tangible and intangible), supporting them to systematically identify and consider certain factors related to the goal fulfillment, and how the factors can be effectively manipulated in the design process (e.g., design for interest by making the interactions novel and complex). This study generates a set of design strategies through a bottom-up and top-down approach. First, the top-down approach investigates the mechanism of awe through the perspective of appraisal theory. Meanwhile, the bottom-up approach explores the patterns of when and how people experience awe in relation to products through a survey in which participants report their personal experiences of awe and design examples. Through an analysis of a variety of designed artifacts that people consider evoking awe, we intend to learn what designs make people feel awe and what aspects of the designs are associated with elicitation of awe, and generate insights on ways in which products can be designed to evoke awe (i.e., design strategies). We first discuss the emotion of awe and its underlying causes based on appraisal theory to develop a theoretical foundation. Then we dive into the study methods and process through which six design strategies are formulated. Next, we describe each design strategy in detail with design examples and suggestions for implementation. The paper ends with a discussion on how the resulting strategies can be applied in design practice and the relevance of focusing on the long-term experiential value of awe, along with future research directions.

\section{Cause of Awe}

There are many different theories explaining the experience of emotions in product design, such as Norman's neurobiological approach [18], Hassenzahl's approach based on universal psychological needs [19], or Desmet's appraisal approach [20]. Appraisal theory says that emotions are elicited from a distinct set of appraisals or assessment patterns [21]. Appraisals serve to evaluate one's needs and environmental conditions based on several factors such as control, pleasantness, and certainty, based on 
which they would classify the situation as beneficial, detrimental, or irrelevant to their well-being, leading to positive or negative emotions [22]. These different emotions enable one to adapt to different environmental demands or opportunities [23]. What is noteworthy is that depending on the person, the same situation can result in different emotions because the ways people appraise the situation can be different, affected by their own values and concerns [24]. This implies that in human-product interactions, the types of emotion are not determined by the product itself, but by the personal concerns and contexts where the product is placed and how it is used, what meanings the user attributes to it, and how the user talks about it $[25,26]$. For example, a smart watch that controls multiple devices may inspire a person with its sophisticated features today, but the same person may be worried by it tomorrow when realizing that its potential to leak their private information. Hence, it is crucial to consider that the emotion can be evoked not only by the designed technology or its appearance but also by the relational meaning of the designed experience, such as personal associations, concerns, social implications of the design, which can serve as points of reference for design conceptualization and evaluation $[26,27]$.

\section{Appraisals of Awe}

Recent research has investigated distinguishing emotions from one another, and in particular, differentiating between positive emotions. Although positive emotions are less differentiated than negative emotions in terms of expressions and action tendencies [22], recent studies have shown that positive emotions could be differentiated by their appraisal patterns [28,29]. In Keltner and Haidt's seminal work [8], they found that awe is evoked by appraisal of (1) perceived vastness and (2) a need for accommodation. Perceived vastness refers to anything that is experienced as larger than the self's ordinary or normal range of experiences. Vastness can be both perceptual, in which something is physically bigger in scale, such as a grove of tall eucalyptus trees. Vastness can also be conceptual, in which an idea may embody immense implications, such as being in the presence of an idol. The second appraisal component is a need for accommodation, in which accommodation refers to the process of modifying our schemas to make sense of the expanded frame of the perceived vastness. Both appraisal dimensions are needed to experience awe because if either component is missing, then the experience is more likely to be closely aligned with a different emotion. For example, accommodation without vastness could be surprise, and vastness without accommodation could be worship or reverence [8].

Awe appraisals patterns have been further evaluated with various behavioral manifestations: awe appraisal patterns involve self-diminishment and high stimulus-focused attention, while decreased self-focused attention [10]. Tong [28] evaluated the appraisal patterns of 13 different positive emotions, in which its findings aligned closely with the findings of Shiota, Keltner [10]. Awe scored low on the "Achievement" factor, reflecting that a goal has been achieved through personal means and control, and likewise high on the "External Influence" factor, reflecting that the events are subject to non-controllable forces. Awe also scored low on the difficulty factor, reflecting the appraisal of a non-problematic and pleasant experience. Further, most recently, the Awe Experience Scale (AWE-S) has been developed to evaluate awe experiences, using six facets of the awe experience, namely vastness, need for accommodation, altered time perception, self-diminishment, physical sensations, and connectedness [30].

Appraisal theory is particularly useful for the purpose of the current study because it elucidates the underlying principles of awe and proves that the appraisal perspective offers a way of construing the causes of distinct emotions [31]. It was, therefore, decided to use the appraisal patterns of awe (i.e., perceived vastness and a need for accommodation) as a theoretical framework of the current study (top-down). However, the appraisal patterns are not directly applicable to design, because the framework itself does not show how the appraisals can be translated to the design of dynamic interactions with products. While useful in understanding the general conditions that cause awe, this might be too abstract for designers and limited in offering actionable insights in their attempts 
to systematically evoke awe. Therefore, using awe experiences inductively derived from real-world examples stimulated by design and technology (bottom-up), the paper explored how to use the general appraisal patterns (top-down) as the basis for designing for awe.

\section{Exploring the Causes of Awe in Human-Product Interactions}

An online survey (bottom-up) was conducted to explore the causes of awe in human-product interactions. The survey asked for personal experiences and designed artifacts because people are likely to remember moments of awe from their personal experiences due to its transformative and memorable nature [6]. The study consisted of three phases: (1) Collecting examples of awe experience and related designs; (2) analyzing the examples based on theoretical considerations stemming from appraisal theory (top-down); and (3) formulating design strategies.

\subsection{Participants}

Fifteen participants were selected through convenience sampling to participate in this study. The recruited participants' age ranged between 18 and 23 and all currently attending university.

\subsection{Procedure}

The survey started with offering the concept of awe and a prototypical example. The participants were first given an example of what an awe experience might feel like:

"You are walking up a hill through thick woods. It was raining earlier, but the rain stopped a short time ago, and the sun is now shining. All of a sudden, you come to a clearing near the top of the hill and enter a beautiful meadow filled with wildflowers and butterflies. A clear stream is running through the meadow and there is a rainbow in the sky. Off in the distance you can see the snow-capped peaks of a nearby mountain range."

This awe experience vignette was taken from Differentiation of Positive Emotions Scale (DOPES), a validated tool for measuring positive emotions [23]. Participants were provided with a blank PowerPoint presentation deck with instructions to describe awe experiences and awe-evoking artifacts. They were guided to first recall at least three different moments in which they experienced awe and to include a photo with a written description of their responses. Next, they were asked to find and report at least ten different designed artifacts that evoked awe, ranging from products, spaces, art, video, and so forth, and to include a photo and written description. Appendix A reports the included survey instruction.

\subsection{Data Analysis}

For two weeks, 185 design examples were collected in total. Responses that did not relate to the definition of awe, based on its two appraisals of perceived vastness and a need for accommodation were excluded. The process resulted in the collection of 150 design examples of awe. A thematic analysis was conducted to search for patterns in verbal descriptions of the awe cases, in which repeated words or synonymous words were grouped together with their respective images to form a pattern [32]. For example, multiple awe cases used phrases like "bizarre," "frenetic beats," "energy," "vigor," or "cacophony of instruments." These words were grouped into a pattern that described the design to be perceived as "unpredictable" and "fast paced." Another example of phrases that were grouped included: "walking the same steps as the founders," "glimpse into the past," "clearly from the future and the past at the same time," "connection with past and present." These phrases allowed us to observe the pattern that many of the awe-evoking designs described a relationship with time.

We decided to examine the design strategies underlying the chosen design examples following a method used in similar studies investigating how design can be manipulated to facilitate certain experiences, such as strategies to incite surprise [5], dilemma [33], and well-being related symbolic meaning [34]. The authors examined the images of products together with the descriptions of the 
product experiences through the lens of a theoretical framework, revealing the underlying design strategies that are both more direct or literal (e.g., appearance and behavior) and more abstract or metaphorical (e.g., symbolic association). In this study, the visual analysis supplemented the verbal descriptions and based on the similarities of keywords and design qualities, the design examples were grouped via affinity diagramming [35]. The process was iterative and complete when no more changes were made, resulting in a collage of awe design examples per affinity group.

\section{Results}

The affinity groups were then translated into concrete design strategies. The patterns that described the effects of awe rather than eliciting conditions of awe were screened. For example, one pattern was that many people contemplate humanity, humanity's progress, and innovation, and what it means to be human. However, this pattern did not necessarily tell us anything about how the design was made but some of the behavioral effects of awe. Additionally, other patterns could be broken down further and be created by a mix of different design strategies. For example, one pattern that emerged from the design examples was the sense of otherworldliness created by the user's immersion in the design. However, further analysis revealed that immersion was the combination of overwhelmingly high complexity and perception of hierarchy, rather than a standalone strategy. Lastly, each design strategy needed to relate back to the main two appraisals of awe: vastness and need for accommodation. The design strategy, novelty with overwhelmingly high complexity, for example, could be related to these appraisals: the overwhelming complexity of the design could create a sense of vastness as the user observed what seemed to be an infinite amount of detail, and the novelty of the design stimulated the need for accommodation, as the user tried to adjust their schema to a new perspective.

Once the strategies were identified, they were categorized based on the three sources of product emotions proposed by Desmet and Roeser [27] to identify the ways in which awe was evoked in the interactions with the artifacts (see Figure 1). The first source of emotion comes from perceiving the design with the senses, such as seeing, touching, and hearing it (e.g., "I love my action camera because of its clutter-free shape and hard texture."). The second source of emotion comes from using, operating, and managing the design, such as the enjoyment of using its functions or interactive qualities (e.g., "I am relieved because of my action camera's automatic backup function, which enables me to keep and access the memories of my family trip."). The third source of emotion comes from the social implications of the design, such as emphasizing one's identity or relationship with others (e.g., "the pictures I posted on social media well illustrate my energetic and explorative character and gained me some fame in the photo community).

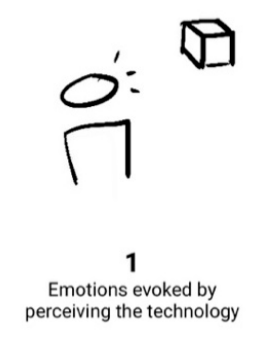

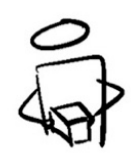

2

Emotions evoked by

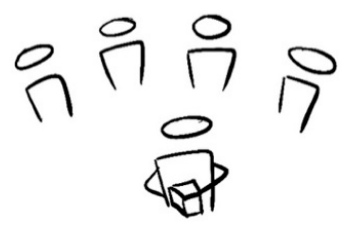

Emotions evoked by Emotions evoked by
technology

Figure 1. Three sources of emotions in human-product interactions (adapted from Desmet and Roeser [27]).

Based on these three overarching categories of perceiving the design, using the design, and social implications of the design, six design strategies were further categorized. The strategies were clustered and categorized based on their similarity in terms of their causes guided by the framework. For example, design Strategy 4 and 5 on novelty, complexity, and unpredictable behavior were categorized underneath perceiving the design with perception-focus. Based on the narratives and the context in which these strategies were used, the stimulation from perceiving the design itself was 
considered what evoked awe. In this case, the design did not need to be used, nor did it inspire any associations with social implications. Figure 2 shows how the strategies were classified based on the three sources of product emotions.

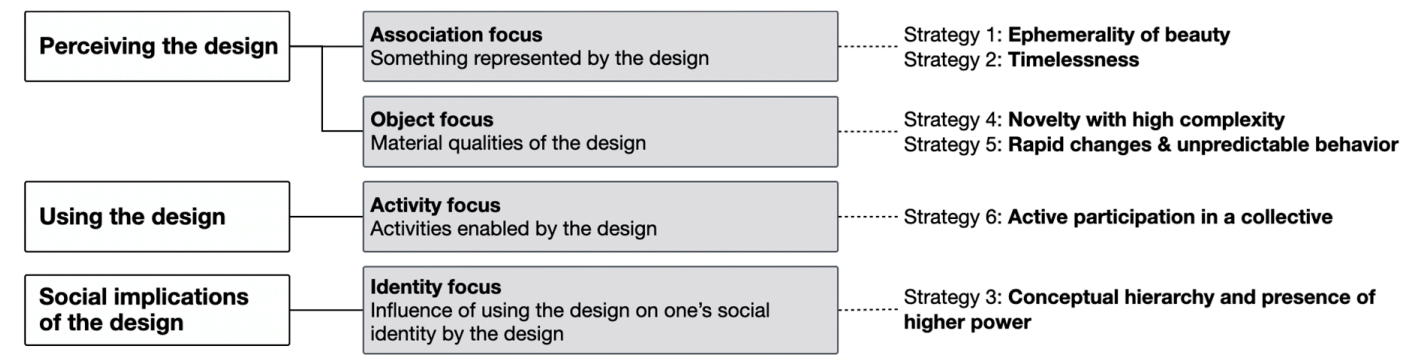

Figure 2. Overview of design strategies within their respective emotion source categories.

\section{Six Strategies to Design for Awe}

This section describes the resulting six strategies to design for awe. Each of the six strategies is detailed with the following structure: how the strategy supports elicitation of awe, how the source of emotion is related to the awe appraisal pattern, associated design examples provided by the participants, and how to apply the strategy to design a product in a concrete and specific way, i.e., implementation. The suggestions for strategy implementation were derived from the descriptions of participants' awe experiences in relation to the chosen artifacts and their aspects. Note that the implementation suggestions are based on the ways that we observed the strategies being applied in the collected data. There can be a wide range of alternative ways each of the strategies can be utilized to manipulate the design. Figure 3 proves a comparative overview of the six strategies.

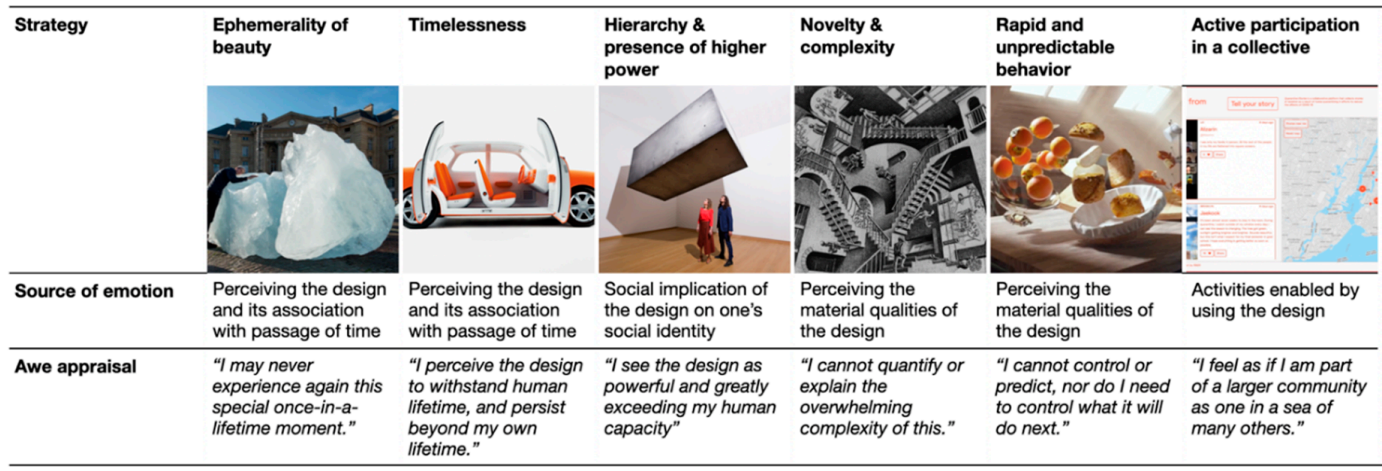

Figure 3. An overview of the six strategies to design for awe.

\subsection{Design Strategy 1-Ephemerality of Beauty}

One strategy to evoke awe is by creating a design that embodies ephemerality of beauty. The source of awe comes from perceiving the design and its association with the passage of time. Passage of the time is in line with awe's appraisal pattern: perceived vastness and need for accommodation. The temporal scarcity of the design may lead people to realize that their resources (e.g., time on earth) are temporary and that they may have witnessed a moment that they may not ever experience again. This "once in a lifetime" mentality can create perceived vastness, as they realize that this experience is one small moment within the many years of their lifetime. The unpredicted change in perspective from one's day-to-day view, to a lifetime view, stimulates a need for accommodation.

\subsubsection{Examples}

Some examples that use this strategy to create a transient aesthetic experience include fireworks and water features such as fountains (Figure 4a). Other examples of nature experiences are blossoming 
flowers, the changing color of leaves during fall, or sunset and sunrise. One participant described walking through a path during the fall and seeing the changing colors: "It was a combination of all the colors I liked, so I had to stop walking and take a moment to just take it in and appreciate how beautiful it was. At that moment, I felt thankful that I was able to see something like that by chance [ ... ]" (Figure 4b). Use of transient materiality is also often used by artists: two participants described a light sculpture installation by TeamLab in which the light beams change orientation to create a unique shape and pattern every time: "[ . . ] light and music pirouette before my eyes. Entranced, I lose a sense of time and space, embraced by an entity which swathes me in light and sound" (Figure 4c). Similarly, Olafur Elaisson used melting ice in his art piece, Ice Watch, to evoke awe by displaying the transience of nature's beauty (Figure 4d).

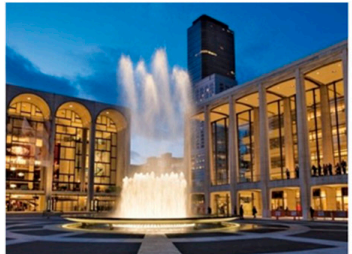

(a)

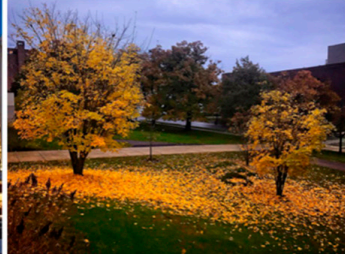

(b)

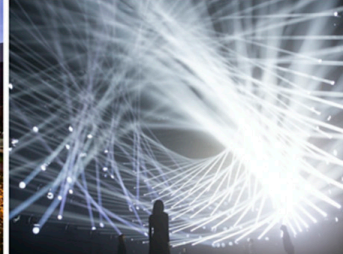

(c)

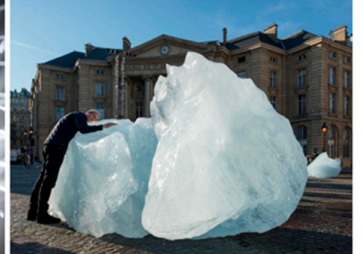

(d)

Figure 4. Examples suggested by the participants (Reprinted with permission): (a) Lincoln Center fountains, (b) leaves changing color, (c) TeamLab light sculpture, and (d) Ice Watch

\subsubsection{Implementation}

To apply the design strategy in a concrete way, designers can create products, spaces, or installations that satisfy two components: beauty and changing appearance of the design. While beauty is a subjective quality, the general goal should be to create a design that people may appreciate and desire to experience again $[36,37]$. In the collected examples, beauty was addressed by, in general, incorporating organic complexity, such as patterns in nature, using colors. For example, in the participant's description of leaves changing color specifically points out that it was the "combination of all the colors" that made her pause and reflect, which reveals one way this design strategy can be implemented (Figure $4 \mathrm{~b}$ ). The participant's description of TeamLab's light sculpture reveals another implementation possibility, when he described the movement of light and sound as "pirouette" and "swathes." These verbs imply organic motion, which is another way this strategy of ephemeral beauty can be implemented. The changing appearance component of the design can be achieved through many means such as using shifting patterns, making the design disappear or disintegrate, or using transient and non-solid materiality such as water, fog, wind, or light, as evidenced in the collected data. Three of the above four examples use manipulation of non-solid materials to create a transient and ephemeral effect. If the design is beautiful but not changing in appearance, it will likely evoke other positive emotions such as inspiration or pride, but not awe. Only when beauty and transience are combined, can we get the effect, in which the person does not try to analyze but rather stands back and appreciates the design, creating that moment for reflection on the passage of time.

\subsection{Design Strategy 2-Timelessness}

Another strategy that evokes awe is to create a timeless design. Timeless designs connote a sense of endurance and are often considered as classics or icons. Similar to the previous strategy, the source of awe comes from perceiving the design and its association with the passage of time. However, this time the method, through which the association is formed, is different. The enduring qualities of the design remind people that the design has persisted beyond one's own lifespan. This mentality can stimulate perceived vastness, as they realize that they are only one of the many thousands of people who have used or experienced the design. The unpredicted change in perspective from one's lifetime to the design's timeline of existence, stimulates a need for accommodation. In line with awe's behavioral impact, fulfillment of the appraisals makes us feel small and insignificant in comparison. 


\subsubsection{Examples}

One design example of this strategy is Marc Newson's Ford 021c (Figure 5a), which uses a neo-retro style to achieve timeliness: "Marc Newson's [ ... ] Ford 021c remains my favorite car ever. [ ... ] This is so clearly from the future and the past at the same time. It does not care about the status quo. It entices me to take it for a spin like no other car does." Another example is the Capitol building in Washington D.C. (Figure 5b) which has become a timeless landmark through its decades-long existence. "What was truly awe-inspiring at this moment was realizing that I was walking the same steps as the founders of this country had while they were doing the work that I had only read about in history textbooks." Participants listed examples of personal experiences and products, or technology that represented human race's achievements and expressed thoughts about how far we have come and where we will go in their personal lives or in regarding humanity as a whole.

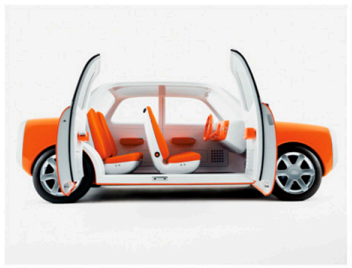

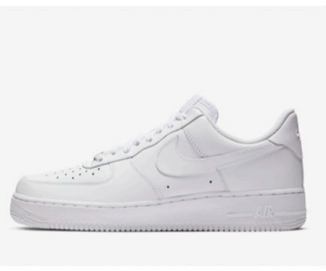

(b)

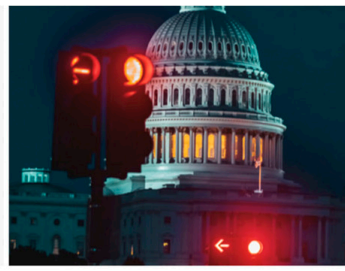

(c)

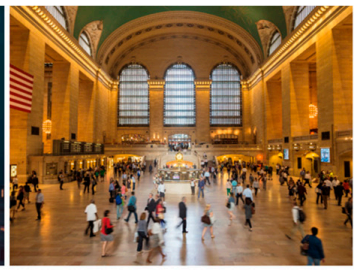

(d)

Figure 5. Examples suggested by the participants (Reprinted with permission): (a) Ford 021c concept car, (b) Nike Air Force 1, (c) Capitol building, and (d) Grand Central station.

\subsubsection{Implementation}

Creating a timeless design may seem very abstract to a designer. Some designs become timeless naturally with age, as with most landmarks and architectural designs like the Capitol building or Grand Central station (Figure 5c,d). However, as observed in the collected design examples, there are ways to apply this strategy in a concrete way, such as creating designs that are deprived of trendy aesthetics. The Nike Air Force 1 is an example of this implementation suggestion (Figure 5b). The participant described the design as "iconic and simple," "bland and minimalistic, yet these qualities are exactly what makes the shoes awe-inspiring." The participant attributed its timeless and iconic qualities to the lack of ornamentation. As suggested by Lobos [38], to achieve timelessness, designers could strive for simplicity by refraining from aesthetic cues that may indicate time markers such as particular trends. Another way to achieve timelessness can be by using a neo-retro design style [39]. Marc Newson's Ford 021c was described by the participant as "clearly from the future and past at the same time" (Figure 5a). Neo-retro products have design characteristics from the past but are also technologically advanced with new functionalities [40].

\subsection{Design Strategy 3-Conceptual Hierarchy and Presence of Higher Power}

The strategy, conceptual hierarchy, and presence of higher power, mean to perceive a power dynamic in which we are lower in status relative to the designed object. The source of awe comes from the social implications of the design, which allows us to define our identity relative to the higher power. The appraisal component "perceived vastness" is achieved when the user realizes that the design is vastly more powerful through its ability to significantly exceed the human capacity in some way, as well as the enormous number of people that the design can affect. The result is a shift in how we understand our identity: from a more egotistical perspective, in which we are the center of the world, to a mindset in which we are merely a subject of something greater, stimulates another appraisal component "a need for accommodation." 


\subsubsection{Examples}

Participants' responses included the Tesla Cybertruck (Figure 6a): "The car also has a presence when you stand next to it, it almost feels like a living beast, ready to roar to life." Designs that evoke a sense of power and hierarchy included being in the presence of an idol or leader, and looking up at a massive monument were also some of the most common awe examples. One participant attended a concert for one of his favorite artists and felt in awe of the artist (Figure 6b): "An inspiration for my music and life, in the flesh. There was a tightness in my throat and I fought back tears. I couldn't stop saying 'wow'." One participant's response, describing listening to a rock band (Figure 6c), exemplifies using immersion to evoke awe: "I remember sitting next to my record player and just listening through the entire album with my eyes closed. I felt so physically small amidst the sound." The art piece, Drifter, by Studio Drift of what appears to be a huge cement block floating in the ceiling (Figure 6d), also conjures awe because its size and placement in the air make it look more powerful.

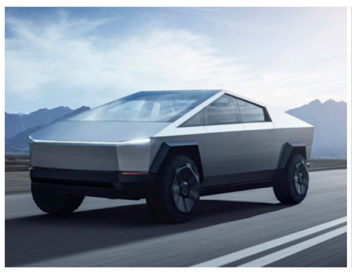

(a)

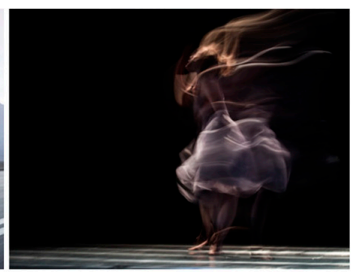

(b)

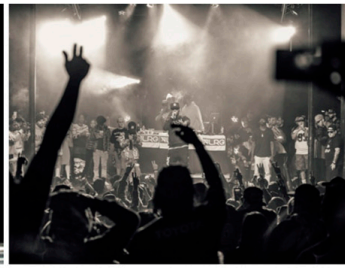

(c)

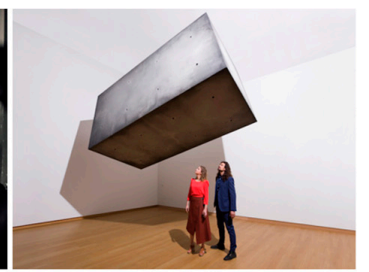

(d)

Figure 6. Examples suggested by the participants (Reprinted with permission): (a) Tesla cybertruck,

(b) artist concert performance, (c) listening to music, and (d) Drifter.

\subsubsection{Implementation}

The strategy can be manifested in design through a variety of means as long as the design appears and feels more powerful than its context with the user. One simple way is to create a stark contrast between the design and its surroundings, making the design appear more powerful and giving it more presence. It is common to place the design on a pedestal or stage, against a backdrop of the opposite color, or high up from the ground to make it stand out more and reinforce the hierarchy. Some designs also rely on their sheer size or appearing massive relative to its surroundings to make the design feel more powerful. Drifter, for example, uses this strategy by contrasting the block to humans to create a sense of scale and hierarchy (Figure 6d). The participant wrote, "how could it be that such a massive concrete block could hang like that? It made me realize that I am so small and powerless in comparison." Another manifestation is to use immersion and surround the user with the design, thereby making them feel small relative to their surroundings. This approach was commonly observed in the collected examples of physical installations and spatial configurations. Yayoi Kusama's Infinity Mirrors was a commonly cited design that inspired awe. One participant wrote, "you are surrounded by an infinite expanse of light, with a pool of water underneath your feet. You are closed into the space, and truly feel transported to another dimension."

\subsection{Design Strategy 4-Novelty with Overwhelmingly High Complexity}

One strategy to evoke awe is by creating a novel design that is highly complex. The source of awe comes directly from perceiving the design and its complex qualities, which may include detailed intricacy, repeated patterns, or an abstract concept that is difficult to grasp. When viewing an overwhelmingly complex design with those qualities, the person is likely to feel a perceived vastness because it is impossible to quantify what may seem like an infinite amount of repetition or ineffable complexity. The design's novel aspects could lead people adjust their perspective to make a sense of what they are experiencing or cope with the complexity, which can stimulate a need for accommodation. 


\subsubsection{Examples}

One example of a design that employs this strategy is Ai Wei Wei's artwork of 100 million handmade porcelain sunflower seeds (Figure 7a). The design is simultaneously novel and complex since it may look like sand or stone from afar, but once you approach closely to it, you realize that the floor is laden with intricate seeds. The complexity comes from the incomprehensible number of seeds and their individual delicacy. Similarly, two participants described Agnes Denes' works, such as the Fibonacci sequence pyramid (Figure $7 \mathrm{~b}$ ): "She hand wrote the sequence, and the pyramid of numbers spanned a 10-foot long table. This felt awe-inspiring because I can tell it took forever to make/feels very labor-intensive, and I was trying to imagine the number of hours that she had to pour into making something so meticulous." The process of understanding abstract theories can also be awe-inspiring because of their vast applicability. One participant described learning about quotient topologies and its relation to the Mobius strip (Figure 7c): " ... Not only could I connect the math to the physical, but I made a broader connection too, that this was the reason I did the math." Another participant described M.C. Escher's staircase drawing (Figure 7d), which also captures both novelty and complexity at the same time: "M.C. Escher's drawings seem impossible and conceivable at the same time, especially his staircase illusions. The sense of awe comes from commonplace objects being manipulated in an unexpected way. I feel awe because I can't understand what's going on, but it seems familiar and correct at the same time."

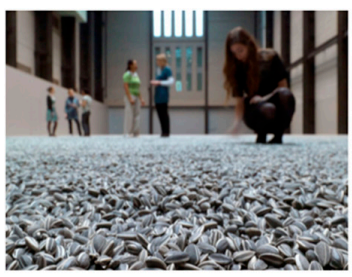

(a)

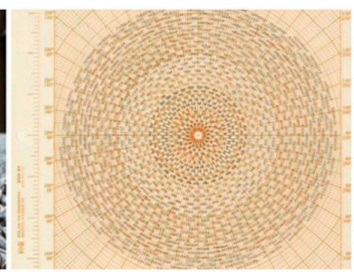

(b)

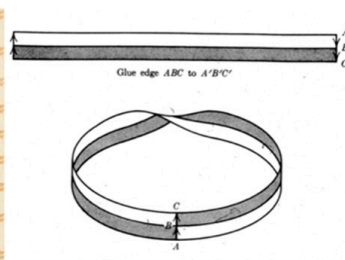

(c)

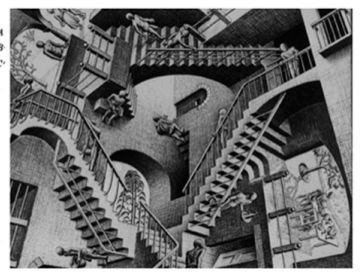

(d)

Figure 7. Examples suggested by the participants (Reprinted with permission): (a) Ai Wei Wei sunflower seeds, (b) Agnes Denes Fibonacci sequence pyramid, (c) Mobius strip, and (d) M.C. Escher staircase illusion.

\subsubsection{Implementation}

Novelty may be subjective since what is novel to one person, may not be for another. However, novelty can be more concretely implemented by considering a mismatch between expectations and reality $[5,41]$. As described by the participant who wrote about M.C. Escher's staircase, she ascribed the sense of awe to "commonplace objects being manipulated in an unexpected way." Something that looks new can have familiar qualities (i.e., visual novelty), and something that looks familiar may have new qualities (i.e., hidden novelty). For example, a mason jar made from lightweight plastic will create hidden novelty since it looks familiar but has unfamiliar materiality. Complexity can be achieved by incorporating intricate repeating patterns, as seen in the collected data. For example, one participant described egg carving: "seeing such beautiful intricate patterns on the eggshell knowing how fragile it is to work with inspires a sense of awe: both at the work itself and at the time, effort, and skill of the artist." Optical illusions, such as M.C. Escher's staircase, can also create complexity, as well as novelty, since the effect of the design changes depending on the person's location and perspective. The use of large numbers can also conceptually convey a sense of complex, infinite, and unquantifiable vastness since numbers or theories are an abstract representation that can feel difficult to grasp. For example, the sheer magnitude of Ai Wei Wei's 100 million porcelain seeds and Agnes Denes' 10 foot-long pyramid of numbers, makes the design almost inconceivable, as described by the participant: "I was trying to imagine the number of hours [ ... ] into making something so meticulous." Ultimately, the design should not be easily quantifiable or analyzable based on its appearance to ensure its high complex character. 


\subsection{Design Strategy 5-Rapid Changes and Unpredictable Behavior}

The strategy "rapid changes and unpredictable behavior" means that the designed object or experience should not be fully controllable by the user, and its quality (e.g., appearance) keeps changing. The source of awe mainly comes from perceiving the design and engaging its design qualities with one's senses. By experiencing the unpredictable nature of the design and how it rapidly floods and overwhelms the senses, its vastness is perceived. Similar to the previous strategy, the inability to quantify or immediately analyze the design creates a sense of vastness as we become overwhelmed with the changes. The unpredictable behavior also makes one realize that she/he cannot control the situation and that many things in life are subject to a higher power. The lack of control over the design shifts us from our day-to-day perspective, combined with overwhelming new information, inciting a need for accommodation. This strategy could also be used in combination with the strategies "ephemerality of beauty," "conceptual hierarchy and presence of higher power," and "novelty with overwhelming complexity." The design's unpredictable nature is likely to enhance the other strategies in fulfilling the two appraisal components of awe: perceived vastness and need for accommodation.

\subsubsection{Examples}

Participants' examples included digital experiences such as videos and animations in which random and abrupt changes disorient the viewer. One participant added an example of a video in which objects start to randomly fly in many directions out of the blue (Figure 8a): "It was completely unexpected and mind-blowing since there's no indication that something crazy like that will happen. And when he opens the door, we're once again surprised that he's floating in space. The sudden and unexplained changes left me in awe as I tried to process what was happening as quickly as possible." In another example, the participant described going to a DJ set (Figure 8b): "Seiho spins a mix of frenetic beats while ripping insane keyboard solos. The music's energy, his vigor, and flashing lights made this video especially awe-inspiring."

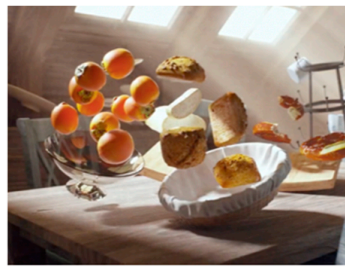

(a)

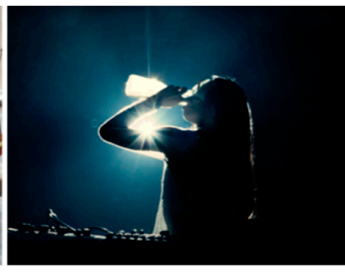

(b)

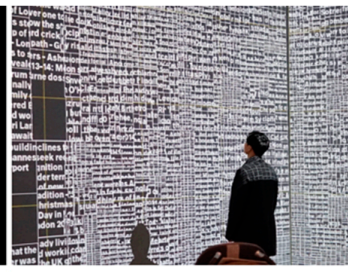

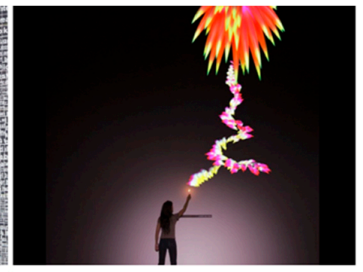

(d)

Figure 8. Examples suggested by the participants (Reprinted with permission): (a) flying objects video, (b) Seiho DJ set, (c) kinetic typography by LUST, and (d) Light my fire by Sigmasix.

\subsubsection{Implementation}

Both components of rapid changes and unpredictable behavior appeared critical to evoke awe. If the design is just unpredictable but not instantaneous enough, the user would be confused or frustrated. If the design changes its appearance rapidly but predictable, the user may feel bored. Rapid changes can be expressed in design by flashing lights, screens, or animations. A physical product, such as a kaleidoscope, could also quickly change in patterns and colors. These implementation options are exemplified in Seiho's DJ set and the video of flying objects in which the changes in lighting, music, and imagery were characterized as "frenetic" and "sudden." The unpredictable behavior component means that the product or experience should minimize having user controls or interfaces to directly manipulate the design. As observed in the data points for this design strategy, most designs were videos, installations, or events, in which user controls were limited.

\subsection{Design Strategy 6-Active Participation in a Collective}

The last design strategy describes evoking awe through a participatory activity in which many people can partake simultaneously to work towards a common goal or interest. The source of awe 
comes from the consequences of directly using the design and what the design enables us to do. The design's direct interaction with multiple people or the representation of many people creates a sense of vastness because they are surrounded by a sea of people or their visual representation. The user realizes that she/he is not alone, but rather part of a much larger community or group, and this shift in perspective induces a need for accommodation. As a result, they experience awe and its effects, such as feeling connected with others.

\subsubsection{Examples}

Many participants cited examples of going to a concert or working in a team as awe-inspiring moments, in which they are surrounded by people. One participant described going to see her favorite band (Figure 9a): "This combination of effects made me feel a sense of mystery and strangeness. I felt very connected to everyone around me who shared my love of Beach House. I felt very close to being overwhelmed with my emotion." Some experiences can also be an abstract representation of contributing to a larger group, such as the TeamLab aquarium, where you can draw a fish to contribute to the pool (Figure 9b). By looking at the pool of swimming fish made by so many different kids surrounding your own fish, a visualization of the community that facilitates a new perspective is created.

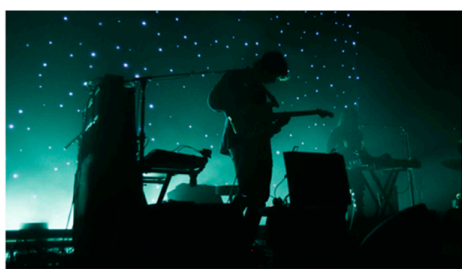

(a)

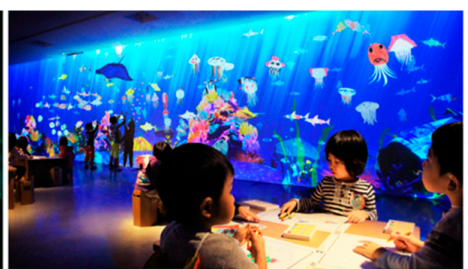

(b)

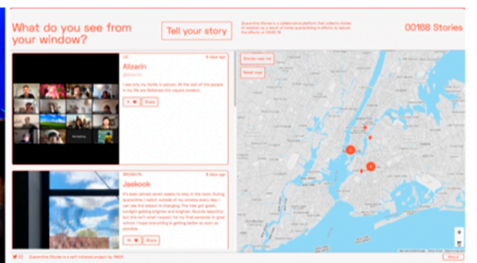

(c)

Figure 9. Examples suggested by the participants (Reprinted with permission): (a) Beach House concert, (b) TeamLab aquarium, and (c) Quarantine Stories by RNDR.

\subsubsection{Implementation}

This strategy can be directly manifested in design that invites and allows multiple to participate in its usage simultaneously by incorporating multiple affordances that indicate collective use. The experience can be further facilitated by incorporating some aspects that invite its participants to take collective action toward a common goal. For example, one participant described the artwork of I WAS HERE by Laura Schnitger: "the sequin tapestry is made unique by the everyday people walking by and leaving their marks [... ]. The exhibit itself is special because people come and go, leaving behind traces of themselves for other people to see and interact with." If the design cannot directly engage multiple people, then a visual representation of other people's presence and their contribution can be helpful in encouraging others to contribute to the collective. TeamLab's aquarium, for instance, allows the user to upload their drawings into the digital ocean, and displays the scanned drawings of every individual, conveying each user's contribution to the collective presence.

\section{Discussion}

\subsection{Suggestions on How to Use the Design Strategies}

This paper introduced six design strategies to facilitate the experience of awe. A theoretical concept needs to be translated into actionable design strategies that can be applied efficiently in academic and design practice settings to create a real-world impact. Löwgren [42] proposed that design knowledge can be represented with the dimension of abstraction: general theory, on the one hand, and particular artifacts on the other hand. There is an intermediate-level design knowledge that enables designers to bridge the two opposites. Examples of such knowledge include design strategies, patterns, and annotated portfolios [43]. By conveying real-world examples (bottom-up) and the underlying theoretical account (top-down), the six design strategies fit in the space of intermediate-level design 
knowledge. Although we have not yet applied the strategies into design cases, we would like to offer some considerations for the utilization of the strategies. The resulting six strategies can make two major contributions to design processes. As a source of inspiration and confirmation, they can assist designers in (1) envisioning design ideas that evoke awe and (2) assessing their effectiveness. In this section, implications of the design strategies will be drawn for each of these two areas.

The first area of application is to guide the early stages of design conceptualization where the six strategies can support designers to envision experiences that could enable intended users to feel awe. This study explored a variety of design elicitors and eliciting conditions beyond the simulation of nature experiences. Types of design examples ranged from art exhibits, interior spaces, architecture to physical products, videos, theories, and concepts. Some of the most frequently cited examples were art installations like Kusama's infinity mirrors or TeamLab's Borderless, and architectural spaces like Grand Central Station or the Oculus, a circular opening in the center of a dome or in a wall. These examples are congruent with the previous studies on awe-inspiring contexts such as musical theater [44], rock music festivals [45], immersive built environments [46,47]. Besides, beyond these suggestive contexts, the collection of design examples included a wide array of manifestations, e.g., consumer products, services, and social media. This comprehensiveness could make the resulting design strategies more widely applicable to varying design contexts because they illustrate how the experience of awe can be stimulated by means of various design manifestations. Besides, the strategies show three different ways in which users feel awe in relation to design: perceiving the design, using the design, and associating the design with its social implications. The accounts of these different ways of experiencing awe can support designers to explore diverse design directions beyond imitating typical awe-stimulating conditions (e.g., projecting nature imageries onto a large screen). Hence, it is expected that the six strategies categorized by the three emotion sources can spark inspiration and guide the process of concept generation in such a way that the design solution fits the given design context and users.

The second area of application is to assess new designs' potential to evoke awe. One of the strengths of using the appraisal framework is that designers are enabled to understand the underlying reasoning for why and how each design strategy could work to evoke awe. This understanding will hopefully equip designers to devise an overarching design goal (i.e., addressing vastness and a need for accommodation), against which they make more informed evaluations regarding the design's effectiveness to evoke awe in the early stages of product development. For example, if their design does not seem to evoke awe based on user feedback, they can return to the appraisals and ask themselves: do the users appraise this design with vastness and need for accommodation? At a more concrete level, each of the strategies can serve as points of reference for examining the design. For example, designers could assess if the initial design concept stimulates their users to perceive a conceptual hierarchy (strategy 3 ) or enables the users to actively participate in a collective effort (strategy 5). Additionally, the analysis of the participants' awe experiences and design examples showed three different ways in which awe can be experienced based on the emotion source framework $[27,48]$. Elucidating the underlying process of awe in human-product interactions and the different pathways through which awe can be evoked (i.e., the three sources of awe) is what makes the proposed design strategies concrete and useful for methodically assessing how the design would evoke awe.

\subsection{Addressing the Experiential Value of Awe Holistically}

Apart from the strategies "active participation in a collective" and "conceptual hierarchy and presences of power," other strategies did not involve direct interaction with the product (i.e., perceiving the design; see the sources of emotion depicted in Figure 2). This implies that in experiencing awe, it may be inevitable that users have a limited sense of control. In a similar vein, the fourth strategy, "novelty with overwhelmingly high complexity," and fifth strategy, "rapid changes and unpredictable behavior," may lower users' competence to some degree. In fact, the resulting strategies appear to align with the previous studies on the causes of awe; awe is evoked when one 
appraises a lack of personal means and control [28]. Their usefulness in systematically evoking awe aside, these potential negative effects of using the strategies raise a question: "Is it appropriate to utilize these strategies to evoke awe at the risk of hindering users' ability to control?" Previous work on usability and user experience focused primarily on short-term efficient use, functional effectiveness, and the immediate hedonic effects on users, following the utilitarianism that pursues a maximization of pleasure and minimization of pain $[49,50]$. In this view, the fourth strategy, "novelty with overwhelmingly high complexity," and fifth strategy, "rapid changes and unpredictable behavior," may appear to contrast with general design recommendations. Low novelty-complexity is associated with high usability, and high novelty-complexity is associated with low usability [51].

Indeed, while awe is considered a positive emotion due to its beneficial behavioral effects for oneself and others, it is known to involve negative experience as antecedents of awe [8]. Other similar positive emotions at the fringes of the distinction between positive and negative emotions are hope and relief as they require the appraisal of uncertainty in their elicitation (for an overview of how positive emotions can be distinguished from negative emotions, see [52]). We want to emphasize that here, the explicit transformational effects of awe, such as prosocial and sustainable behaviors $[6,7,12]$, is the key driver of designing for awe. Although many design approaches mainly focus on minimizing negative emotions (e.g., making a user interface familiar, thereby making it less difficult to understand), we argue that making use of both positive and negative emotions is crucial because different situations demand different emotions [24]. Negative emotions can sometimes be inevitable and even beneficial. For example, as extensively studied in psychology (for an overview, see [53]), anger enables people to rectify an unfair situation instead of pursuing short-term comfort and avoiding arguments. Envious people are more determined to achieve their goals, and under certain circumstances, fear can make an experience more enjoyable and richer (e.g., riding a rollercoaster) [54]. According to Fokkinga and Desmet [54], the benefits of specific negative emotions can deliberately serve as a design intention in enriching users' experience. They suggest that addressing the positive effects of negative emotions calls for creation of a "protective frame." This frame refers to the mental construct that enables people to create a certain psychological distance between themselves and the stimulus [55] (e.g., enjoying the awe and terror being close to a lion in the cage). The frame is known to be the most critical factor that detracts the unpleasant aspects from the potentially negative experience while leaving the transforming effects intact [56].

Especially in well-being-focused design initiatives that focus on long-term effects of design, e.g., Positive Design [57] and Experience Design [19], it is suggested that design takes a more holistic approach by accepting that negative experiences are part of our life and should be embraced; certain well-being enhancing experiences (e.g., committing to one's goals and developing strategies for coping) are not a straightforward process but involves setbacks and relapses. In accordance with these design initiatives, we argue that in designing for awe, the strategies that potentially engender a negative moment could be purposefully used for fostering the experiential value of awe in the long run. This implies that the product as a mediator of awe experiences should be in the focus of attention, and the process of evoking awe needs to focus on the design's essence-wider effects of awe on experience and behavior. In this effort, we call for a balanced and sensible user-centered design approach that considers users' acceptability, contextual factors, along with long-term benefits for users beyond instant gratifications.

\section{Conclusions}

The exploration into designing for awe and transformative experiences continues to expand. In the fields of design and human-computer interaction, there has been a shift from building new products and technologies that simply support human activity, such as communication and productivity, to creating a design that can support fulfillment of higher needs such as transcendence [58]. In this study, we followed an appraisal theory approach toward designing for awe. Awe's appraisals (i.e., need for accommodation and perceived vastness) served as the guideline to evoking awe. The main contribution 
to the field of design is the six design strategies that help designers evoke awe. The particular design examples suggested by the participants were abstracted into broad design strategies that could be used to create new products with the potential of eliciting awe. Each strategy relates back to the appraisals by showing how the strategy is congruous with the appraisal pattern of awe. Based on the examples identified by the study's participants, the strategies were further elucidated to explain how they could be applied to the design. We believe that the resulting design strategies and concrete design examples will help designers systematically create products that will enable users to experience awe, personal growth and transformation in the long run.

\subsection{Limitations}

Many participants had difficulty finding ten compelling design examples, and some responses appeared to be non-awe related, referring to other positive emotions such as surprise and shock. This could be due to the lack of a consensual definition of awe. Our study used an excerpt that described the experience of awe through a vignette, which was taken from the Differentiation of Positive Emotions Scale [23]. The vignette describes entering a nature scene. However, because this was the only input for the participants, it might have biased people into more frequently talking about nature experiences. Recently a scale that measures awe experiences [30] has been developed that uses various keywords that are indicative of an awe experience, such as altered time perception, self-diminishment, connectedness, perceived vastness, physical sensations, and need for accommodation. We postulate that using these keywords with the vignette could have better helped participants' understanding of the meaning of awe.

It was occasionally difficult to interpret based on some participants' descriptions as to whether or not awe was actually experienced because some of the explanations lacked detail as to what part specifically about the design they felt like evoked awe, or how they felt from experiencing the design. This leads to the second limitation: the study's internal validity would have benefited from a second researcher to participate in the thematic analysis and the categorization of the strategies into the emotion sources. While thematic analysis is flexible for analyzing qualitative data, this flexibility can lead to inconsistency and a lack of coherence when developing themes derived from the data [59]. Hence, a future research opportunity would be to replicate this study, with different samples of participants and varying product types, and involve multiple researchers in the data analysis process to ensure internal validity.

Although this study does not intend to cover all possible experiences of awe in human-product interactions, it is important to consider that the participants' ages ranged between 18 and 23 may limit the types of design examples provided. People's experiences with emotion-eliciting situations largely differ as they age [60], and the types of experiences and designs that they may be exposed to differ as well. Therefore, we invite initiatives aiming to refine and expand the resulting strategies across different samples, stimuli, and situations. The culture-specific sample of participants may also affect results because culture can play a role in the priming of people and influence subsequent judgment and interpretation. Depending on how people are primed, the way they appraise a design can vary [61]. This implies that the design strategies' applicability might not be cross-cultural. Hence, it is important to conduct a user-centered and participatory research study when designing for emotion. It allows the designer to gain an in-depth understanding of the context and users' concerns (e.g., goals, values, and aspirations) that reveals how different people from varying cultural backgrounds might react to the design, and whether the design evokes awe. Reflecting on our experience, it is suggested that design strategy implementation should be based on the insights shared and checked with the actual users, and not rely on the strategy alone, in order to make sure that the final design is developed to have the intended emotional impact.

\subsection{Future Work}

The design strategies generated in this study can be used to inform the creative process of developing a product that evokes awe. It is assumed that some strategies would be more preferable 
for designers or considered easier to address than others. Further research should be undertaken to investigate how the strategies can be effectively applied to design. The questions that could be asked include: how can designers be supported to choose an appropriate strategy that is highly relevant to the design challenge at hand? How can the strategies and related contents be effectively conveyed to designers? It would be beneficial to involve designers and other stakeholders who may use the strategies, which would help methodically address needs and expectations of those who will actually use the strategies in practice.

Another future direction would be to conduct a study that evaluates whether users feel awe-inspired by interacting with the product, which was designed using the proposed strategies. We postulate that the effects of such product will be dependent on the utilized strategy and the design context (e.g., education, healthcare, shopping, etc.). Future research can focus on determining whether a certain design strategy is more effective for evoking awe experiences in a certain context than others. In particular, the study would benefit from investigating if the short- and long-term behavioral and cognitive effects of awe could be replicated in human-product interactions, such as the perception of small self $[9,30]$, the shift of attention from individual interests and concerns to social collectives [16], and the promotion of systematic cognitive processing for persuasion [62].

Author Contributions: Conceptualization, J.K. and J.Y.; methodology, J.K. and J.Y.; formal analysis, J.K.; writing —original draft preparation, J.K.; writing—review and editing, J.Y.; visualization, J.K. and J.Y.; supervision, J.Y. Please turn to the CRediT taxonomy for the term explanation. Authorship must be limited to those who have contributed substantially to the work reported. All authors have read and agreed to the published version of the manuscript.

Funding: This research was supported by Cornell Center for Social Sciences.

Acknowledgments: We would like to thank Michael Goldstein for his constructive feedback on earlier versions of this paper. We express our gratitude to the copyright owners of the photographs for their permission to use them in the manuscript. We also would like to thank the reviewers for their very helpful comments.

Conflicts of Interest: The authors declare no conflict of interest.

\section{Appendix A. Instruction and Questions Used in the Survey}

What might awe feel like? In order to discuss awe experiences, I would like to provide an example of what an awe-inspiring experience might look like. Envision this experience for instance:

You are walking up a hill through thick woods. It was raining earlier, but the rain stopped a short time ago, and the sun is now shining. All of a sudden, you come to a clearing near the top of the hill and enter a beautiful meadow filled with wildflowers and butterflies. A clear stream is running through the meadow and there is a rainbow in the sky. Off in the distance you can see the snow-capped peaks of a nearby mountain range.

Your awe-inspiring experiences could have felt mind-blowing, breathtaking, made you say "wow", gave you goosebumps, or even moved you to tears. These are just some of the common reactions that people have when they experience awe.

\section{Appendix A.1. Section 1: Recalling Past Experiences of Awe}

Take a moment to think about past experiences that you've had that were awe-inspiring. You might want to answer: What happened and what were you doing? How would you express your feelings? How did you respond? What was on your mind?

Write a short paragraph per memory, describing both the memory itself and what about the experience might have caused you to feel awe. Please also include an image that represents your memory as close as possible. Submit a minimum of 3 responses, one slide per response/memory.

\section{Appendix A.2. Section 2: Awe Examples}

Find a minimum of 10 designs that would evoke the emotion of awe within you. With the term "design," I mean any kind of artifact that you can imagine such as space, consumer product, 
installations, online services, etc. These designs could be taken from websites, Instagram and social media, magazines, Youtube, something you randomly encountered during your day, and beyond.

Please include an image and a short description of what aspect of the design or experience evokes awe.

\section{Appendix B. Image Credits}

Figure 4c (Title: Light Evaporating with People II, Credit: teamLab, Exhibition view of teamLab Borderless, 2019, Shanghai (c) teamLab, courtesy Pace Gallery); Figure 4d (Title: Ice Watch, Credit: Ice Watch, 2014, by Olafur Eliasson and Minik Rosing, Martin Agryroglo photography); Figure 5a (Title: Ford 021C Concept Car, Credit: Ford 021C Concept Car, 1999, Marc Newson Ltd. and Ford, Tommaso Sartori photography); Figure 6d (Title: Drifter, Credit: Drifter, 2017, DRIFT and SkySpirit at Amory Show); Figure 7a (Title: Sunflower Seeds, Credit: Sunflower Seeds, Ai Wei Wei, 2010, Photo: (C) Tate, London 2020); Figure 7c (Reprinted by permission from Springer Science: Algebraic Topology: An Introduction, William S. Massey (C) 1977); Figure 8a (Title: Dreaveler, Credit: Dreaveler, 2018, by Taehoon Park at Pause Fest Motion Response 2018); Figure 8d (Title: Light My Fire, Credit: Light My Fire, 2008, by Florian Pittet, Ecal x SIGMASIX); Figure 9a (Beach House live at the House of Blues in Boston, 2018, by John Hutchings on Vanyaland.com. Link: https://bit.ly/2IEWVpm); Figure 9b (Title: Sketch Aquarium, Credit: teamLab, Exhibition view of teamLab Borderless, 2018, Tokyo (C) teamLab, courtesy Pace Gallery); Figure 9c (Title: Quarantine Stories, Credit: Quarantine Stories, 2020, by RNDR. Link: http://quarantinestories.today).

\section{References}

1. Fredrickson, B.L. The role of positive emotions in positive psychology. Am. Psychol. 2001, 56, $218-226$. [CrossRef] [PubMed]

2. Yoon, J.; Pohlmeyer, A.E.; Desmet, P.M.A. When 'feeling good' is not good enough: Seven key opportunities for emotional granularity in product development. Int. J. Des. 2016, 10, 1-15.

3. Lu, Y.; Roto, V. Design for pride in the workplace. Psychol. Well Being 2016, 6, 6. [CrossRef] [PubMed]

4. Yoon, J.; Desmet, P.M.; van der Helm, A. Design for interest: Exploratory study on a distinct positive emotion in human-product interaction. Int. J. Des. 2012, 6, 67-80.

5. Ludden, G.D.; Schifferstein, H.N.; Hekkert, P. Surprise as a design strategy. Des. Issues 2008, 24, 28-38. [CrossRef]

6. Gaggioli, A. Transformative experience design. In Human Computer Confluence Transforming Human Experience through Symbiotic Technologies; Gaggioli, A., Ferscha, A., Riva, G., Dunne, S., Viaud-Delmon, I., Eds.; De Gruyter: Berlin, Germany, 2016; pp. 97-121.

7. Kitson, A.; Buie, E.; Stepanova, E.R.; Chirico, A.; Riecke, B.E.; Gaggioli, A. Transformative experience design: Designing with interactive technologies to support transformative experiences. In Extended Abstracts of the 2019 CHI Conference on Human Factors in Computing Systems; Association for Computing Machinery: New York, NY, USA, 2019.

8. Keltner, D.; Haidt, J. Approaching awe, a moral, spiritual, and aesthetic emotion. Cogn. Emot. 2003, 17, 297-314. [CrossRef]

9. Piff, P.K.; Dietze, P.; Feinberg, M.; Stancato, D.M.; Keltner, D. Awe, the small self, and prosocial behavior. J. Pers. Soc. Psychol. 2015, 108, 883-899. [CrossRef]

10. Shiota, M.N.; Keltner, D.; Mossman, A. The nature of awe: Elicitors, appraisals, and effects on self-concept. Cogn. Emot. 2007, 21, 944-963. [CrossRef]

11. Yang, Y.; Bao, T.; Liu, Y.; Passmore, H.-A. Elicited awe decreases aggression. J. Pac. Rim Psychol. 2016, 10, 10. [CrossRef]

12. Wang, L.; Zhang, G.; Shi, P.; Lu, X.; Song, F. Influence of awe on green consumption: The mediating role of psychological ownership. Front. Psychol. 2019, 10,1-11. [CrossRef]

13. Rudd, M.; Hildebrand, C.; Vohs, K.D. Inspired to create: Awe enhances openness to learning and the desire for experiential creation. J. Mark. Res. 2018, 55, 766-781. [CrossRef]

14. Chirico, A.; Ferrise, F.; Cordella, L.; Gaggioli, A. Designing awe in virtual reality: An experimental study. Front. Psychol. 2018, 8, 2351. [CrossRef] [PubMed] 
15. Stepanova, E.R.; Quesnel, D.; Riecke, B.E. Space-A virtual frontier: How to design and evaluate a virtual reality experience of the overview effect. Front. Digit. Humanit. 2019, 6, 7. [CrossRef]

16. Bai, Y.; Maruskin, L.A.; Chen, S.; Gordon, A.M.; Stellar, J.E.; McNeil, G.D.; Peng, K.; Keltner, D. Awe, the diminished self, and collective engagement: Universals and cultural variations in the small self. J. Pers. Soc. Psychol. 2017, 113, 185. [CrossRef] [PubMed]

17. Corn, J. Awe and astonishment: Wonder in the age of democratized magic. In Products of Design; School of Visual Arts: New York, NY, USA, 2017.

18. Norman, D.A. Emotional design: Why We Love (or Hate) Everyday Things; Basic Books: New York, NY, USA, 2004.

19. Hassenzahl, M. Experience Design: Technology for All the Right Reasons; Morgan \& Claypool: San Rafael, CA, USA, 2010.

20. Desmet, P.M.A. Designing Emotions; Delft University of Technology: Delft, The Netherlands, 2002.

21. Lazarus, R.S. Emotion and Adaptation; Oxford University Press: Oxford, UK, 1991.

22. Ellsworth, P.C.; Smith, C.A. Shades of joy: Patterns of appraisal differentiating pleasant emotions. Cogn. Emot. 1988, 2, 301-331. [CrossRef]

23. Kirby, L.D.; Tugade, M.M.; Morrow, J.; Ahrens, A.H.; Smith, C.A. Vive la Différence: The ability to differentiate positive emotional experience and well-being. In Handbook of Positive Emotions; Tugade, M.M., Shiota, M.N., Kirby, L.D., Eds.; The Guilford Press: New York, NY, USA, 2014; pp. 241-255.

24. Frijda, N.H. The Laws of Emotion; Lawrence Erlbaum Associates Publishers: London, UK, 2007.

25. Haddon, L. Roger Silverstone's legacies: Domestication. New Media Soc. 2007, 9, 25-32. [CrossRef]

26. Filippi, S.; Barattin, D. Exploiting the meCUE Questionnaire to Enhance an Existing UX Evaluation Method Based on Mental Models. In Proceedings of the International Conference on Human-Computer Interaction, Copenhagen, Denmark, 19-24 July 2019.

27. Desmet, P.M.A.; Roeser, S. Emotions in design for values. In Handbook of Ethics, Values, and Technological Design; Springer: Dordrecht, The Netherlands, 2015; pp. 203-219.

28. Tong, E.M.W. Differentiation of 13 positive emotions by appraisals. Cogn. Emot. 2014, 29, 484-503. [CrossRef]

29. Smith, C.A.; Tong, E.M.W.; Ellsworth, P.C. The Differentiation of Positive Emotional Experience as Viewed through the Lens of Appraisal Theory; The Guilford Press: New York, NY, USA, 2014; pp. 11-27.

30. Yaden, D.B.; Kaufman, S.B.; Hyde, E.; Chirico, A.; Gaggioli, A.; Zhang, J.W.; Keltner, D. The development of the Awe Experience Scale (AWE-S): A multifactorial measure for a complex emotion. J. Posit. Psychol. 2019, 14, 474-488. [CrossRef]

31. Desmet, P.M.A. Product emotion. In Product Experience; Hekkert, P., Schifferstein, H.N.J., Eds.; Elsevier: London, UK, 2008; pp. 379-397.

32. Braun, V.; Clarke, V. Using thematic analysis in psychology. Qual. Res. Psychol. 2006, 3, 77-101. [CrossRef]

33. Ozkaramanli, D.; Desmet, P.M.A.; Ozcan, E. Beyond resolving dilemmas: Three design directions for addressing intrapersonal concern conflicts. Des. Issues 2016, 32, 78-91. [CrossRef]

34. Casais, M.; Mugge, R.; Desmet, P. Objects with symbolic meaning: 16 directions to inspire design for well-being. J. Design Res. 2018, 16, 247-281. [CrossRef]

35. Tomitsch, M.; Wrigley, C. Design. Think. Make. Break. Repeat; Bis Publishers: Amsterdam, The Netherlands, 2018; p. 208.

36. Hassenzahl, M. Aesthetics in Interactive Products: Correlates and Consequences of Beauty; Elsevier: Amsterdam, The Netherlands, 2008; pp. 287-302.

37. Jacobsen, T.; Buchta, K.; Köhler, M.; Schröger, E. The primacy of beauty in judging the aesthetics of objects. Psychol. Rep. 2004, 94, 1253-1260. [CrossRef] [PubMed]

38. Lobos, A. Timelessness in sustainable product design. In Proceedings of the International Conference on Design and Emotion, Bogota, Colombia, 6-10 October 2014.

39. Wallner, T.S.; Magnier, L.; Mugge, R. An exploration of the value of timeless design styles for the consumer acceptance of refurbished products. Sustainability 2020, 12, 1213. [CrossRef]

40. Schiavone, F.; Castellano, S.; Adnane, M.; Safraou, I.; Fort-Rioche, L.; Ackermann, C.L. Consumer innovativeness, perceived innovation and attitude towards "neo-retro"-product design. Eur. J. Innov. Manag. 2013, 16, 495-516. 
41. Filippi, S.; Barattin, D. Considering users' different knowledge about products to improve a UX evaluation method based on mental models. In Proceedings of the International Conference of Design, User Experience, and Usability, Las Vegas, NV, USA, 15-20 July 2018.

42. Löwgren, J. Annotated portfolios and other forms of intermediate-level knowledge. Interactions 2013, 20, 30-34. [CrossRef]

43. Gaver, B.; Bowers, J. Annotated portfolios. Interactions 2012, 19, 40-49. [CrossRef]

44. Greenacre, L.; Freeman, L.; Filby, J.; Ostrovsky, T. My-music my-self. Qual. Mark. Res. Int. J. 2015, 18, 145-160. [CrossRef]

45. Chaney, D.; Goulding, C. Dress, transformation, and conformity in the heavy rock subculture. J. Bus. Res. 2016, 69, 155-165. [CrossRef]

46. Sherry, J.F., Jr.; Kozinets, R.V.; Storm, D.; Duhachek, A.; Nuttavuthisit, K.; DeBerry-Spence, B. Being in the zone: Staging retail theater at ESPN Zone Chicago. J. Contemp. Ethnogr. 2001, 30, 465-510. [CrossRef]

47. Kozinets, R.V.; Sherry, J.J.F.; Storm, D.; Duhachek, A.; Nuttavuthisit, K.; DeBerry-Spence, B. Ludic agency and retail spectacle. J. Consum. Res. 2004, 31, 658-672. [CrossRef]

48. Desmet, P.M.A. Faces of product pleasure: 25 positive emotions in human-product interactions. Int. J. Des. 2012, 6, 1-29.

49. Desmet, P.M.A.; Hassenzahl, M. Towards Happiness: Possibility-Driven Design; Zacarias, M., de Oliveira, J.V., Eds.; Springer: Berlin/Heidelberg, Germany, 2012; pp. 3-27.

50. Diefenbach, S.; Kolb, N.; Hassenzahl, M. The 'hedonic' in human-computer interaction: History, contributions, and future research directions. In Designing Interactive Systems; ACM: New York, NY, USA, 2014; pp. 305-314.

51. Mahlke, S.; Minge, M.; Thüring, M. Measuring Multiple Components of Emotions in Interactive Contexts; ACM: New York, NY, USA, 2006; pp. 1061-1066.

52. Watson, D.; Wiese, D.; Vaidya, J.; Tellegen, A. The two general activation systems of affect: Structural findings, evolutionary considerations, and psychobiological evidence. J. Personal. Soc. Psychol. 1999, 76, 820-838. [CrossRef]

53. Parrott, W.G. The Positive Side of Negative Emotions; Guilford Publications: New York, NY, USA, 2014.

54. Fokkinga, S.; Desmet, P.M.A. Darker shades of joy: The role of negative emotion in rich product experiences. Des. Issues 2012, 28, 42-56. [CrossRef]

55. Apter, M.J. Danger: Our Quest for Excitement; Oneworld Publications: London, UK, 2006.

56. Apter, M.J. Reversal Theory: The Dynamics of Motivation, Emotion, and Personality; Oneworld Publications Limited: London, UK, 2007.

57. Desmet, P.M.A.; Pohlmeyer, A.E. Positive design: An introduction to design for subjective well-being. Int. J. Des. 2013, 7, 1-15.

58. Gaggioli, A.; Riva, G.; Peters, D.; Calvo, R.A. Positive Technology, Computing, and Design: Shaping a Future in Which Technology Promotes Psychological Well-Being; Jeon, M., Ed.; Elsevier: Amsterdam, The Netherlands, 2017; pp. 477-502.

59. Holloway, I.; Todres, L. The status of method: Flexibility, consistency and coherence. Qual. Res. 2003, 3, 345-357. [CrossRef]

60. MacCormack, J.K.; Henry, T.R.; Davis, B.M.; Oosterwijk, S.; Lindquist, K.A. Aging bodies, aging emotions: Interoceptive differences in emotion representations and self-reports across adulthood. Emotion 2019. [CrossRef] [PubMed]

61. Hong, Y.Y.; Morris, M.W.; Chiu, C.Y.; Benet-Martinez, V. Multicultural minds: A dynamic constructivist approach to culture and cognition. Am. Psychol. 2000, 55, 709. [CrossRef] [PubMed]

62. Griskevicius, V.; Shiota, M.N.; Neufeld, S.L. Influence of different positive emotions on persuasion processing: A functional evolutionary approach. Emotion 2010, 10, 190. [CrossRef] [PubMed]

Publisher's Note: MDPI stays neutral with regard to jurisdictional claims in published maps and institutional affiliations. 